\title{
Investigation of one-lung ventilation postoperative cognitive dysfunction and regional cerebral oxygen saturation relations ${ }^{* \#}$
}

\author{
Xi-ming $\mathrm{LI}^{\dagger 1}$, Feng $\mathrm{LI}^{2}$, Zhong-kai LIU ${ }^{1}$, Ming-tao SHAO ${ }^{\dagger \dagger 3}$ \\ $\left({ }^{1}\right.$ Department of Anesthesiology, Linyi City People's Hospital, Linyi 276000, China) \\ $\left({ }^{2}\right.$ Human Resource Department, Linyi City People's Hospital, Linyi 276000, China) \\ $\left({ }^{3}\right.$ Department of Emergency Surgery, Linyi City People's Hospital, Linyi 276000, China) \\ †E-mail: 13515397176@163.com; bcxqywb@163.com \\ Received Jan. 29, 2015; Revision accepted July 6, 2015; Crosschecked Nov. 30, 2015
}

\begin{abstract}
Objective: To explore the relationship of postoperative cognitive dysfunction (POCD) in one-lung ventilation (OLV) patients and regional cerebral oxygen saturation $\left(\mathrm{rSO}_{2}\right)$. Methods: Twenty-nine male and twenty-one female cases of OLV received thoracic surgery, with American Standards Association (ASA) physical status being at Grades I-III. Neuropsychological tests were performed on the day before operation and $7 \mathrm{~d}$ after operation, and there was an intraoperative continuous monitoring of $\mathrm{rSO}_{2}$. The values of $\mathrm{rSO}_{2}$ before anesthesia induction $\left(t_{1}\right)$, at the beginning of OLV $\left(t_{2}\right)$, and at the time of OLV $30 \mathrm{~min}\left(t_{3}\right)$, OLV $60 \mathrm{~min}\left(t_{4}\right)$, the end of OLV $\left(t_{5}\right)$, and the end of surgery $\left(t_{6}\right)$ were recorded. The intraoperative average of $\mathrm{rSO}_{2}\left(\overline{\mathrm{rSO}}_{2}\right)$, the intraoperative minimum value of $\mathrm{rSO}_{2}\left(\mathrm{rSO}_{2}\right.$, min $)$, and the reduced maximum percentage of $\mathrm{rSO}_{2}\left(\mathrm{rSO}_{2}\right.$ \% max $)$ when compared with the baseline value were calculated. The volume of blood loss, urine output, and the amount of fluid infusion was recorded. Results: A total of 14 patients (28\%) in the 50 cases suffered from POCD. The values of mini-mental state examination (MMSE), the digit span and the digit symbol on the 7th day after the operation for POCD in OLV patients were found to be significantly lower than those before the operation $(P<0.05)$. The values of MMSE and vocabulary fluency scores were significantly lower than those in the non-POCD group $(P<0.05)$. The values of $\mathrm{rSO}_{2}$ in the POCD group of OLV patients at $t_{2}$ and $t_{3}$ and the values of $\mathrm{rSO}_{2}$ in the non-POCD group at $t_{2}$ were found to be significantly higher than those at $t_{1}(P<0.05)$. The values of $\mathrm{rSO}_{2}$, \% max in the POCD group were significantly higher than those in the non-POCD group $(P<0.05)$. When the value of $\mathrm{rSO}_{2}$ \% max is more than $10.1 \%$, it may act as an early warning index for cognitive function changes. Conclusions: POCD after OLV may be associated with a decline in $\mathrm{rSO}_{2}$.
\end{abstract}

Key words: One-lung ventilation, Postoperative cognitive dysfunction, Regional cerebral oxygen saturation doi: 10.1631 jzus.B1500030

Document code: A

CLC number: R74; R61

\section{Introduction}

After surgery and anesthesia, many patients notice a decline in cognitive function, especially memory. This condition is called postoperative cognitive dysfunction (POCD), and it is present for weeks or months after surgery (Rasmussen, 2006).

\footnotetext{
Corresponding author

* Project supported by the Foundation of Shandong Science and Technology Project (No. 2011YD18070), China

\# Part of this article is reproduced and translated with permission from J. Clin. Anesthesiol., 2013, 29(1):53-56

(ib) ORCID: Xi-ming LI, http://orcid.org/0000-0002-4428-9550

(C) Zhejiang University and Springer-Verlag Berlin Heidelberg 2015
}

POCD is detected by administration of a neuropsychological test battery. The first major study of long term POCD in humans reported an incidence of $25.8 \%$ one week after surgery and $9.9 \%$ after three months (Moller et al., 1998).

Studies on POCD have focused on the impact of increasing age or poor education, as well as perioperative factors including the type of surgery. Accumulated evidence suggests that POCD is linked to surgery (Hong et al., 2008). One-lung ventilation (OLV) is widely used in operations in the Department of Thoracic Surgery. This non-physiological ventilation can put the ratio of ventilation and blood flow 
into imbalance, which increases the pulmonary flow, resulting in hypoxemia, ventilation perfusion imbalance, pulmonary ischemia-reperfusion, and other physiological disorders, and can lead to the release of various cytokines and trigger systemic inflammatory response. However, it is unknown whether these factors are associated with POCD.

Proposed interventions to modify these factors include monitoring of regional cerebral oxygen saturation $\left(\mathrm{rSO}_{2}\right)$ (Casati et al., 2005; Slater et al., 2009). However, evidence is lacking on any association of intraoperative $\mathrm{rSO}_{2}$ with patients' outcome and POCD using structured cognitive testing. Transcranial near-infrared spectroscopy (NIRS) provides a non-invasive method to detect $\mathrm{rSO}_{2}$. Recent studies have shown that the development of POCD has a significant relationship with the levels of $\mathrm{rSO}_{2}$ in patients undergoing coronary artery bypass graft (CABG) (Olsen et al., 1996; Murkin et al., 2007).

This study was performed on patients with OLV. The objective of this study was to evaluate the predictive value of intraoperative $\mathrm{rSO}_{2}$ in relation to the occurrence of early (1 week) POCD in an elderly population with this kind of operation using a complete array of neuropsychological tests. It was hypothesized that there would be a relationship between the severity of $\mathrm{rSO}_{2}$ and POCD occurrence in the early post-operative period.

\section{Materials and methods}

\subsection{Materials}

The general data: 50 patients underwent OLV thoracic operation (lung, esophagus) in our hospital from December, 2011 to May, 2012, and all cases were in American Standards Association (ASA) Grades I-III, with 29 male cases and 21 female cases, aged $40-75$ years, body height being $160-174 \mathrm{~cm}$, body weight being $54-72 \mathrm{~kg}$, the OLV time being above $30 \mathrm{~min}$, and preoperative heart and lung function being normal. All patients were approved by the Medical Ethics Committee of the hospital and signed their informed consent. Exclusion criteria: severe hypertension, heart disease; already existing cognitive impairment confirmed by preoperative mini-mental state examination (MMSE) examination; anxiety and other mental illness, mental disorder; cognitive impairment with head injury; senile dementia, stroke squealed, cerebral hemorrhage, and other important organ function failure; disease leading to interference in the evaluation of cognitive functions, including drug or other psychiatric drug abuses, neural function defect associated with aphasia, blindness, serious hemiplegic, visual disorder, etc. Ten cases of normal people were chosen to form the normal control group with age and gender composition ratio matched.

\subsection{Anesthetic management}

All patients received a standardized anesthetic management. After entering the operating room, a MINDRAY T8 multi parameter monitor was used to establish the electrocardiogram (ECG), heart rate (HR), blood oxygen saturation $\left(\mathrm{SpO}_{2}\right)$, end-tidal $\mathrm{CO}_{2}$ pressure $\left(\mathrm{PetCO}_{2}\right)$, and other conventional monitoring. A radial artery catheter was used to measure invasive blood pressure. After the degreasing treatment with alcohol cotton ball cleaning for forehead skin, Narcotrend $^{\mathbb{B}}$ electrodes were applied to the forehead to record the data. Intravenous injections of midazolam of $0.08-0.10 \mathrm{mg} / \mathrm{kg}$, propofol of $1-2 \mathrm{mg} / \mathrm{kg}$ and sufentanil of $0.8-1.0 \mu \mathrm{g} / \mathrm{kg}$ were given. Cisatracurium of $0.10-0.15 \mathrm{mg} / \mathrm{kg}$ was given under general anesthesia. After denitrogenation and oxygenation for 3-5 min, double lumen end tracheal intubation was conducted, and a fiber optic bronchoscope was used to confirm the position. Internal jugular vein punctures were performed and a bronchoscope was used to check the tracheal catheter's position. The anesthesia machine was used to give pure oxygen for $1-5 \mathrm{~L} / \mathrm{min}$. To maintain appropriate anesthetic depth, the inhalation concentration of sevoflurane was adjusted.

NIRS was used for $\mathrm{rSO}_{2}$ monitoring. An $\mathrm{rSO}_{2}$ probe was placed in the right prefrontal part of the head after stabilization. The instrument can be used for continuous monitoring, automatic recording and the preservation of cerebral oxygen data, recording twice every minute, and transmitting the data to a computer for statistical processing after the operation.

Anesthesia was maintained with continuous intravenous infusion of sevoflurane of $1 \%-3 \%$, propofol of $2-5 \mu \mathrm{g} /(\mathrm{kg} \cdot \mathrm{min})$, remifentanil of $0.5-1.0 \mu \mathrm{g} /(\mathrm{kg} \cdot \mathrm{min})$, and cis-atracurium of $2-4 \mu \mathrm{g} /(\mathrm{kg} \cdot \mathrm{min})$. Blood pressure (BP) and HR fluctuations were controlled within the basal value of $30 \%$. The inhalation anesthetic was stopped when subcutaneous suture was performed and continuous intravenous infusion of propofol was 
used to maintain anesthesia until the end of skin closure. Volume-controlled ventilation was adopted during anesthesia with tidal volume $\left(\mathrm{V}_{\mathrm{T}}\right)$ being $10 \mathrm{ml} / \mathrm{kg}$. During OLV, $\mathrm{V}_{\mathrm{T}}$ was kept at $6-8 \mathrm{ml} / \mathrm{kg}$. By adjusting the respiratory rate $(\mathrm{RR}), \mathrm{PetCO}_{2}$ was maintained at $35-40 \mathrm{mmHg}(1 \mathrm{mmHg}=133.3 \mathrm{~Pa})$. The oxygen concentration in inhalation was $100 \%$, with the times of inspiration and exhalation (I:E) is $1: 1-2$.

Continuous intraoperative monitoring of $\mathrm{rSO}_{2}$ was performed. The average value of intraoperative $\mathrm{rSO}_{2}\left(\overline{\mathrm{rSO}}_{2}\right)$, the minimum value of intraoperative $\mathrm{rSO}_{2}$ $\left(\mathrm{rSO}_{2}, \mathrm{~min}\right)$, and the maximum decreased percentage of $\mathrm{rSO}_{2}\left(\mathrm{rSO}_{2, \% \max }\right)$ when compared with the basal value were calculated. Intraoperative blood loss, urine volume, and fluids input were recorded routinely.

\subsection{Diagnostic criteria for POCD}

Patients underwent a battery of clinical neuropsychological tests on the day before the operation and on the 7 th day after the operation, and the normal control group received cognitive assessment at the same time interval. The neuropsychological tests includes MMSE, digit span test, digit symbol test, tracking line test A, vocabulary fluency test, and word recognition task. Learning effects were defined as a mean variation of each test among the control subjects. The test score is gained by subtracting the score before the test and then the learning effect, and the result is further divided by the standard deviation of preoperative scores to obtain the $Z$ score. When the $Z$ score is found to be more than 1.96 two or more times, the patients can be recognized with POCD (Moller et al., 1998; Johnson et al., 2002; Canet et al., 2003; Lin et al., 2013).

Table 1 Comparison of the general data in the two groups

\begin{tabular}{lccc}
\hline \multicolumn{1}{c}{ Variable } & $\begin{array}{c}\text { Non-POCD } \\
(n=36)\end{array}$ & $\begin{array}{c}\text { POCD } \\
(n=14)\end{array}$ & $P$-value \\
\hline Age (year) & $54 \pm 9$ & $62 \pm 7^{* *}$ & $<0.01$ \\
Gender (male, \%) & $18(52.9 \%)$ & $11(68.7 \%)$ & 0.245 \\
Weight (kg) & $66.05 \pm 10.48$ & $61.96 \pm 8.69$ & 0.298 \\
Height (cm) & $169.45 \pm 4.89$ & $167.14 \pm 7.08$ & 0.345 \\
Education level illiterate & $1(3 \%)$ & $0(0 \%)$ & \\
$\leq 6$ years & $8(22 \%)$ & $2(14 \%)$ & 0.724 \\
$>6$ years & $27(75 \%)$ & $12(86 \%)$ & \\
Hypertension (yes/no) & $20 / 16$ & $6 / 8$ & 0.163 \\
Diabetes (yes/no) & $6 / 30$ & $2 / 12$ & 0.965 \\
Smoking history (yes/no) & $6 / 31$ & $4 / 10$ & 0.738 \\
Surgical history (yes/no) & $16 / 20$ & $6 / 8$ & 0.665 \\
\hline
\end{tabular}

Data are expressed as mean \pm SD or $n(\%){ }^{* *} P<0.01$ compared with the non-POCD group

\subsection{Statistical analysis}

SPSS 15.0 software was used for analysis. Measurement data underwent the analysis of normality and homogeneity of variance, using the mean \pm standard deviation (SD) or median (four percentile interval) as the results, and the percentage was used for numerical data. The $t$-test was used for interclass measurement data. The $\chi^{2}$ test or Fisher test was used for numerical data analysis.

\section{Results}

\subsection{Incidence of POCD}

After application of the inclusion and exclusion criteria, a total of 50 patients underwent the neuropsychological tests on the day before surgery and on the 7 th day after surgery. POCD occurred in 14 cases, an incidence rate of $28 \%$.

\subsection{Comparison of the intraoperative data be- tween the two groups}

The 50 cases of patients were divided into two groups: the non-POCD group $(n=36)$ and the POCD group $(n=14)$. Comparison was made of the preoperative general data including the possible risk factors associated with POCD between the two groups (Table 1) and the intraoperative information (operation time, OLV time, intraoperative blood loss, intraoperative fluid replacement volume, intraoperative urinary volume; Table 2). There were significant differences in age, OLV, and ventilation time between the two groups $(P<0.05)$.

Table 2 Comparison of the intraoperative data in the two groups

\begin{tabular}{lccc}
\hline \multicolumn{1}{c}{ Variable } & $\begin{array}{c}\text { Non-POCD } \\
(n=36)\end{array}$ & $\begin{array}{c}\text { POCD } \\
(n=14)\end{array}$ & $P$-value \\
\hline Fluid replacement (ml) & $2245.4 \pm 356.7$ & $2385.7 \pm 308.6$ & 0.237 \\
Blood loss (ml) & $453.2 \pm 106.7$ & $503.1 \pm 156.7$ & 0.339 \\
$\begin{array}{c}\text { Duration of anesthesia } \\
\quad(m i n)\end{array}$ & $185.3 \pm 21.3$ & $190.0 \pm 26.2$ & 0.708 \\
Duration of surgery & $156.2 \pm 24.2$ & $186.3 \pm 20.2$ & 0.056 \\
$\quad(m i n)$ & & & \\
OLV time (min) & $90.3 \pm 23.1$ & $123.5 \pm 26.3^{*}$ & 0.043 \\
Urine volume (ml) & $792.0 \pm 56.3$ & $804.2 \pm 58.4$ & 0.464 \\
Remifentanil (mg) & $3.5 \pm 1.1$ & $3.2 \pm 1.3$ & 0.805 \\
Propofol (mg) & $1205 \pm 30$ & $1195 \pm 42$ & 0.726 \\
Cisatricurium (mg) & $13.5 \pm 2.6$ & $12.9 \pm 2.2$ & 0.636 \\
\hline
\end{tabular}

Data are expressed as mean \pm SD. ${ }^{*} P<0.05$ compared with the non-POCD group 


\subsection{Physiological variables}

The content of arterial partial pressure of oxygen $\left(\mathrm{PaO}_{2}\right)$ was higher at $t_{2}-t_{6}$ than at $t_{1}$ in all patients $\left(t_{1}\right.$ : before anesthesia induction; $t_{2}$ : the beginning of OLV; $t_{3}$ : the time of OLV $30 \mathrm{~min} ; t_{4}$ : OLV $60 \mathrm{~min}$; $t_{5}$ : the end of OLV; $t_{6}$ : the end of surgery), which was associated with the inhalation of pure oxygen (Table 3 ). The content of hematocrit (Hct) was lower at $t_{3}-t_{6}$ than at $t_{1}$ between the two groups, which was associated with the blood loss, but no significant difference was found between the two groups.

\subsection{Psychological test}

No significant difference was found between the day before operation and the 7 th day after operation in the non-POCD group. In the POCD group, the postoperative scores of MMSE, digit symbol substitution test (DSST), and verbal fluency test (VFT) were significantly lower than baseline $(P<0.05$; Table 4$)$. No significant difference was found between the two groups on the day before the operation. There existed significantly lower MMSE and vocabulary fluency in the POCD group than in the non-POCD group on the 7 th day after operation $(P<0.05)$.

\subsection{Comparison of $\mathrm{rSO}_{2}$}

The two groups showed no significant difference in $\mathrm{rSO}_{2}, \overline{\mathrm{rSO}}_{2}$, and $\mathrm{rSO}_{2}$, min at $t_{6}$ (Table 5), but the $\mathrm{rSO}_{2, \% \max }$ in the POCD group was significantly higher than that in the non-POCD group $(P<0.05)$.

In the two groups, the $\mathrm{rSO}_{2}$ values at $t_{2}$ were significantly higher than that at $t_{1}(P<0.05)$. In the POCD group, the $\mathrm{rSO}_{2}$ value at $t_{6}$ declined more than that at $t_{1}(P<0.05)$.

\subsection{Predictive value of $\mathrm{rSO}_{2}, \%$ max for POCD}

Fig. 1 displayed the receiver operating characteristic (ROC) curve of $\mathrm{rSO}_{2, \% \max }$. The area under the curve (AUC) was 0.912 (95\% confidence interval (CI) $[0.885,1.000])$. The $95 \%$ percentile was selected as a cut-off point. The $\mathrm{rSO}_{2, \% \max }$ value was $10.1 \%$, the sensitivity of $\mathrm{rSO}_{2,} \% \max$ was $90 \%$, and the specificity was $86.5 \%$ in predicting POCD.

Table 3 Comparison of physiological variables between the two groups

\begin{tabular}{|c|c|c|c|c|c|c|c|c|}
\hline \multirow{2}{*}{ Time } & \multicolumn{2}{|c|}{$\mathrm{pH}$} & \multicolumn{2}{|c|}{$\mathrm{PaCO}_{2}(\mathrm{mmHg})$} & \multicolumn{2}{|c|}{$\mathrm{PaO}_{2}(\mathrm{mmHg})$} & \multicolumn{2}{|c|}{$\operatorname{Hct}(\%)$} \\
\hline & Non-POCD & POCD & Non-POCD & POCD & Non-POCD & POCD & Non-POCD & POCD \\
\hline$t_{1}$ & $7.36 \pm 0.25$ & $7.37 \pm 0.18$ & $35 \pm 5$ & $35 \pm 6$ & $160 \pm 19$ & $157 \pm 21$ & $36 \pm 5$ & $35 \pm 6$ \\
\hline$t_{2}$ & $7.35 \pm 0.16$ & $7.38 \pm 0.13$ & $36 \pm 7$ & $37 \pm 6$ & $311 \pm 54$ & $301 \pm 34$ & $32 \pm 5$ & $30 \pm 6$ \\
\hline$t_{3}$ & $7.33 \pm 0.22$ & $7.29 \pm 0.24$ & $38 \pm 7$ & $39 \pm 6$ & $322 \pm 21$ & $324 \pm 18$ & $26 \pm 6^{*}$ & $25 \pm 7^{*}$ \\
\hline$t_{4}$ & $7.35 \pm 0.12$ & $7.35 \pm 0.15$ & $44 \pm 6$ & $42 \pm 5$ & $288 \pm 19$ & $291 \pm 16$ & $24 \pm 5^{*}$ & $24 \pm 8^{*}$ \\
\hline$t_{5}$ & $7.36 \pm 0.17$ & $7.42 \pm 0.21$ & $45 \pm 7$ & $45 \pm 6$ & $270 \pm 23$ & $262 \pm 18$ & $23 \pm 8^{*}$ & $23 \pm 5^{*}$ \\
\hline$t_{6}$ & $7.40 \pm 0.12$ & $7.36 \pm 0.11$ & $39 \pm 4$ & $40 \pm 5$ & $203 \pm 26$ & $189 \pm 22$ & $23 \pm 8^{*}$ & $22 \pm 9^{*}$ \\
\hline
\end{tabular}

$\mathrm{PaCO}_{2}$ : partial pressure of arterial carbon dioxide; $\mathrm{PaO}_{2}$ : arterial partial pressure of oxygen; Hct: hematocrit. Data are expressed as mean $\pm \mathrm{SD}$ (non-POCD: $n=36$; POCD: $n=14) .1 \mathrm{mmHg}=133.3 \mathrm{~Pa} .{ }^{*} P<0.05$ compared with the value at $t_{1}$

Table 4 Psychological test results between the two groups

\begin{tabular}{|c|c|c|c|c|c|c|c|c|c|c|}
\hline \multirow{2}{*}{ Group } & \multicolumn{2}{|c|}{ MMSE } & \multicolumn{2}{|c|}{ DSST } & \multicolumn{2}{|c|}{ Trail making test A (s) } & \multicolumn{2}{|c|}{ VFT } & \multicolumn{2}{|c|}{ WRMT } \\
\hline & Pre & Pod\#7 & Pre & Pod\#7 & Pre & Pod\#7 & Pre & Pod\#7 & Pre & Pod\#7 \\
\hline $\begin{array}{c}\text { Non-POCD } \\
\quad(n=36)\end{array}$ & $29.0 \pm 1.2$ & $28.4 \pm 1.7$ & $32.7 \pm 12.2$ & $31.8 \pm 13.7$ & $17.6 \pm 13.8$ & $18.7 \pm 13.9$ & $16.7 \pm 3.5$ & $17.1 \pm 3.4$ & $1.2 \pm 1.4$ & $1.5 \pm 1.2$ \\
\hline $\begin{array}{l}\text { POCD } \\
\quad(n=14)\end{array}$ & $29.6 \pm 0.5$ & $27.1 \pm 1.1^{* *}$ & $31.0 \pm 12.1$ & $23.7 \pm 12.6^{* *}$ & $19.4 \pm 11.0$ & $20.5 \pm 17.1$ & $13.8 \pm 2.7$ & $12.6 \pm 4.6^{* *}$ & $1.3 \pm 1.4$ & $1.9 \pm 1.4$ \\
\hline$P$-value & 0.384 & 0.034 & 0.329 & 0.045 & 0.278 & 0.185 & 0.169 & $<0.001$ & 0.658 & 0.825 \\
\hline
\end{tabular}

Data are expressed as mean \pm SD. ${ }^{* *} P<0.01$ compared with the non-POCD group. Pre: preoperative; Pod\#7: the 7 th day after operation. WRMT: word recognition memory test

Table 5 Comparison of $\mathrm{rSO}_{2}, \overline{\mathbf{r S O}}_{2}, \mathrm{rSO}_{2, \min }$ and $\mathrm{rSO}_{2,}$ max between the two groups

\begin{tabular}{|c|c|c|c|c|c|c|c|c|c|}
\hline \multirow{2}{*}{ Group } & \multicolumn{6}{|c|}{$\mathrm{rSO}_{2}(\%)$} & \multirow{2}{*}{$\begin{array}{c}\overline{\mathrm{rSO}}_{2} \\
(\%)\end{array}$} & \multirow{2}{*}{$\begin{array}{c}\mathrm{rSO}_{2, \min } \\
(\%)\end{array}$} & \multirow{2}{*}{$\begin{array}{c}\mathrm{rSO}_{2, \% \max } \\
(\%)\end{array}$} \\
\hline & $t_{1}$ & $t_{2}$ & $t_{3}$ & $t_{4}$ & $t_{5}$ & $t_{6}$ & & & \\
\hline $\begin{array}{c}\text { Non-POCD } \\
(n=36)\end{array}$ & $\begin{array}{c}70 \\
(69-71)\end{array}$ & $\begin{array}{c}81 \\
(79-83)^{\#}\end{array}$ & $\begin{array}{c}71 \\
(69-74)\end{array}$ & $\begin{array}{c}72 \\
(70-76)\end{array}$ & $\begin{array}{c}70 \\
(66-74)\end{array}$ & $\begin{array}{c}68 \\
(65-72)\end{array}$ & $\begin{array}{c}72 \\
(68-76)\end{array}$ & $\begin{array}{c}63 \\
(59-67)\end{array}$ & $\begin{array}{c}7.8 \\
(6.8-8.8)\end{array}$ \\
\hline $\begin{array}{l}\text { POCD } \\
\quad(n=14)\end{array}$ & $\begin{array}{c}70 \\
(68-72) \\
\end{array}$ & $\begin{array}{c}80 \\
(76-86)^{\Delta}\end{array}$ & $\begin{array}{c}74 \\
(68-77) \\
\end{array}$ & $\begin{array}{c}71 \\
(61-79) \\
\end{array}$ & $\begin{array}{c}67 \\
(59-75) \\
\end{array}$ & $\begin{array}{c}62 \\
(57-68)^{\Delta} \\
\end{array}$ & $\begin{array}{c}68 \\
(61-75) \\
\end{array}$ & $\begin{array}{c}59 \\
(53-65)\end{array}$ & $\begin{array}{c}13.4 \\
(8.2-18.6)^{*}\end{array}$ \\
\hline$P$-value & 0.658 & 0.729 & 0.56 & 0.646 & 0.373 & 0.197 & 0.327 & 0.465 & $<0.05$ \\
\hline
\end{tabular}

Data are expressed as median (four percentile interval). ${ }^{*} P<0.05$ compared with the non-POCD group. ${ }^{\#} P<0.05$ compared with the value at $t_{1}$ in the non-POCD group. ${ }^{\Delta} P<0.05$ compared with the value at $t_{1}$ in the POCD group 


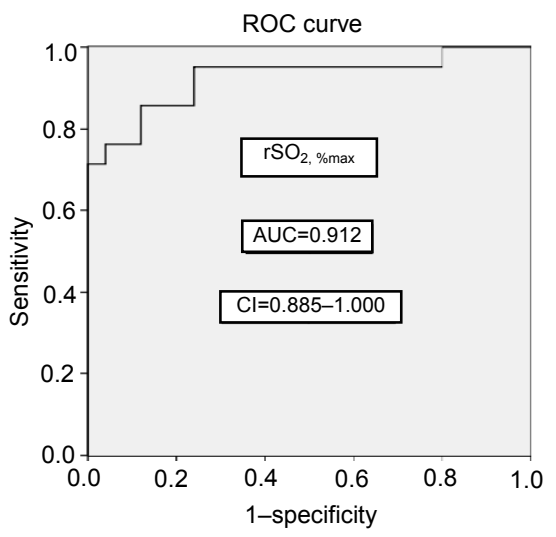

Fig. 1 Receiver operating characteristic (ROC) curves of $\mathrm{rSO}_{2, \% \max }$

AUC: area under the curve; CI: 95\% confidence interval

\subsection{Multiple regression analysis}

The multiple regression analysis showed that age and $\mathrm{rSO}_{2}$ \%max were independent risk factors for the occurrence of POCD (Table 6).

Table 6 Risk factors in relation to POCD

\begin{tabular}{lcc}
\hline Factor & OR & $P$-value \\
\hline Age & 1.426 & 0.041 \\
$\mathrm{rSO}_{2, \% \max }$ & 1.536 & 0.021 \\
\hline
\end{tabular}

OR: odds ratio

\section{Discussion}

POCD, as one of the most serious complications of anesthesia after operation, has attracted research attention over the past 10 years, and a number of clinical and experimental studies have been performed. Previous studies suggested that age, preoperative cognitive dysfunction, preoperative medication (such as anti-cholinergic drugs), and adverse reaction in the operation (such as hypoxia, hypotension) were risk factors of POCD (Moller et al., 1998; Abildstrom et al., 2000; Monk et al., 2008; SinghManoux et al., 2012). However, the pathogenesis of POCD is still not completely clear (Funder et al., 2010). Thoracic operation under OLV, because of its strong stimulation, and OLV-related potential hypoxemia, may also produce an effect on postoperative cognitive function (Karzai and Schwarzkopf, 2009).

The diagnoses of POCD now mainly rely on neuropsychological testing, but there is not yet a unified standard for a POCD neuropsychological test $(\mathrm{Li}$ et al., 2014). The commonly used tests are MMSE, the Wechsler Adult Intelligence Scale (WAIS), and the Wechsler Memory Scale (WMS). The MMSE is now the most influential cognitive defect screening test because of its brevity, easy operation, and good reproducibility. If the MMSE score decreases by more than 2 points, the patients can be recognized as cognitively dysfunctional (Folstein et al., 1975).

The current study was performed by a single person, and some explanation was given to patients. Each patient was given two sets of similar questions before and after surgery, and 10 cases of normal cases formed the control group. The $Z$ scoring method was used to exclude the effect of any learning effects caused by the short-term repeat of two tests (Grilli et al., 1996; Kienlen-Campard et al., 2000; Townsend et al., 2002). The experimental results showed that the two groups of patients with or without POCD had no obvious differences in cognitive functions before the operation. The MMSE, digit span (reverse), and digital symbol test results significantly decreased one week after the operation in the POCD group $(P<0.05)$, and the MMSE and word fluency scores fluency also decreased significantly when compared with the non-POCD group $(P<0.05)$, which may indicate that short-term memory and language expression ability may be damaged.

In this study, POCD occurred in $28 \%$ of patients, which is similar to the $26.1 \%$ in related literature (Karzai and Schwarzkopf et al., 2009). OLV can put the ventilation/perfusion ratio into imbalance, thereby increasing the intrapulmonary shunt, resulting in hypoxemia, ventilation perfusion imbalance, pulmonary ischemia-reperfusion, and other physiological disorders. Although such methods as increasing the inspired oxygen concentration, non-ventilated lung continuous positive airway pressure, ventilated lung positive end expiratory pressure, and block side pulmonary blood flow have been tried to improve the hypoxemia, $5 \%$ to $10 \%$ of patients may still suffer from obvious hypoxemia (Stephan et al., 2003).

$\mathrm{rSO}_{2}$ monitoring can be continuous, noninvasive, and convenient, with high sensitivity and specificity using dual detector proprioceptors. The mixed transmitted intensity of oxygenated hemoglobin and reduced hemoglobin was detected to establish the oxygen saturation of local hemoglobin whose normal value is $55 \%-75 \%$, and may rise on inhalation of pure oxygen (Casati et al., 2005; Farag et al., 2006; Slater et al., 2009). The arteriovenous blood flow ratio in the cerebral blood volume is $15: 85$, so $\mathrm{rSO}_{2}$ mainly represents cerebral venous oxygen saturation and can reflect the balance changes in oxygen supply and 
consumption. The central nervous system is the most sensitive to hypoxia because the demand for oxygen of the brain is very high; brain weight accounts for only $2 \%$ of the whole body weight, but the blood flow in the brain accounts for $15 \%$ of cardiac output and cerebral oxygen consumption accounts for $23 \%$ of total oxygen consumption. The brain is very sensitive to hypoxia, and the normal partial cerebral venous oxygen pressure $\left(\mathrm{PO}_{2}\right)$ is about $34 \mathrm{mmHg}$. When it declines to below $28 \mathrm{mmHg}$, loss of consciousness may occur. And when it declines to $12 \mathrm{mmHg}$, the patient's life may be endangered. Morphological changes of brain tissue induced by hypoxia are mainly brain cell degeneration, necrosis, swelling, and brain edema.

The results showed that when the patients in the two groups had no difference in OLV ventilation time and operation time, patients in the POCD group had their $\mathrm{rSO}_{2}$ significantly decreased, with $\mathrm{rSO}_{2, \% \max }$ in the POCD group significantly higher than that in the non-POCD group $(P<0.05)$, suggesting that low cerebral blood flow perfusion occurred during OLV, with cerebral ischemia and hypoxia. According to some reports, cerebral ischemia may occur when $\mathrm{rSO}_{2}$ was less than $50 \%$ or basic values decreased by more than $20 \%$, and this has been confirmed by an auditory evoked potential test (Blas et al., 1999).

Multi-factor regression analysis showed that age and $\mathrm{rSO}_{2, \% \max }$ were independent risk factors of POCD, and advanced age was also a risk factor $(\mathrm{OR}=1.426$, $P=0.041$ ), which was consistent with the common understanding of POCD. In a large sample of the International Study of Postoperative Cognitive Dysfunction 2 (ISPOCD2), comparing an above 60-yearage group with a 40-60-year-age group, $7 \mathrm{~d}$ after operation $(P=0.0064)$ and 3 months after operation $(P=0.026)$ the younger group had a lower incidence, which may indicate that persistent POCD mainly occurred in the elderly, which may be related to the decrease in the functions of central nervous system and hemodynamic regulation in elderly patients (Johnson et al., 2002). When the elderly renal clearance of drugs and the ability of liver detoxification ability gradually weaken and body fat increases with age, the volume of distribution of lip soluble drugs and elimination of half-life increase and the drug action time was prolonged. All these physiological changes and the trauma stimulation caused by surgical operation as well as physical and mental fatigue may lead to the occurrence of POCD in elderly patients (Silverstein and Jefrey, 2007).
$\mathrm{rSO}_{2, \% \max }$ was closely related to the occurrence of POCD $(\mathrm{OR}=1.536, P=0.021)$, and the area (AUC) below the ROC curve of POCD predicted with $\mathrm{rSO}_{2, \% \max }$ was 0.912 with the $95 \%$ CI $[0.885,1.000]$, which showed good diagnostic value. A percentage of 95\% was chosen as a cut-off point (threshold). When $\mathrm{rSO}_{2, \% \max }$ was more than $10.1 \%$, the sensitivity of $\mathrm{rSO}_{2, \% \max }$ was $90 \%$ and the specificity was $86.5 \%$. $\mathrm{rSO}_{2}$ may become a good tool to predict POCD.

This study also has some shortcomings. The sample size is small and the statistical validity is not sufficient. Because time was limited and the workload of evaluating cognitive function before and after an operation was great, this research only collected the data of 50 patients. The incidence of POCD in this study was higher than that reported in literature and some of the risk factors associated with POCD may not be found out in the multiple regression analysis. Therefore, research with a larger sample size is necessary in future research.

In summary, POCD is a common neurological complication after operative anesthesia. Although there may be many influencing factors and the specific pathogenesis is not yet clear, it deserves more attention.

Strengthening the intraoperative monitoring and OLV management for regular monitoring of $\mathrm{rSO}_{2}$ can help avoid prolonged hypoxia and low $\mathrm{rSO}_{2}$, reduce the incidence of POCD, and improve the prognosis of patients.

\section{Compliance with ethics guidelines}

Xi-ming LI, Feng LI, Zhong-kai LIU, and Ming-tao SHAO declare that they have no conflict of interest.

All procedures followed were in accordance with the ethical standards of the responsible committee on human experimentation (institutional and national) and with the Helsinki Declaration of 1975, as revised in 2008 (5). Informed consent was obtained from all patients for being included in the study. Additional informed consent was obtained from all patients for whom identifying information is included in this article.

\section{References}

Abildstrom, H., Rasmussen, L.S., Rentowl, P., et al., 2000. Cognitive dysfunction 1-2 years after noncardiac surgery in the elderly. Acta Anaesthesiol., Scand., 44(10):12461251. [doi:10.1034/j.1399-6576.2000.441010.x]

Blas, M., Sulek, C., Martin, T., et al., 1999. Use of nearinfrared spectroscopy to monitor cerebral oxygen at ion during coronary artery bypass surgery in a patient with bilateral internal carotid artery occlusion. Cardiothorac. Vasc. Anesth., 13(6):732-735. [doi:10.1016/S1053-0770 (99)90131-3]

Canet, J., Raeder, J., Rasmussen, L.S., et al., 2003. Cognitive dysfunction after minor surgery in the elderly. J. Acta 
Anaesthesiol. Scand., 47(10):1204-1210. [doi:10.1046/j. 1399-6576.2003.00238.x]

Casati, A., Fanelli, G., Pietropaoli, P., et al., 2005. Continuous monitoring of cerebral oxygen saturation in elderly patients undergoing major abdominal surgery minimizes brain exposure to potential hypoxia. Anesth. Analg., 101: 740-747. [doi:10.1213/01.ane.0000166974.96219.cd]

Farag, E., Chelune, G.J., Schubert, A., et al., 2006. Is depth of anesthesia as assessed by bispectral index, related to post-operative cognitive dysfunction and recovery? Anesth. Analg., 103(3):633-640. [doi:10.1213/01.ane.000 0228870.48028.b5]

Folstein, M.F., Folstein, S.E., McHugh, P.R., 1975. "Minimental state": a practical method for grading the cognitive state of patients for the clinician. J. Psychiatr. Res., 12(3):189-198. [doi:10.1016/0022-3956(75)90026-6]

Funder, K.S., Steinmetz, J., Rasmussen, L.S., 2010. Methodological issues of postoperative cognitive dysfunction research. Semin Cardiothorac. Vasc. Anesth., 14(2):119122. [doi:10.1177/1089253210371520]

Grilli, M., Goffi, F., Memo, M., et al., 1996. Interleukin-1 $\beta$ and glutamate activate the NF- $\mathrm{\kappa B} /$ Rel binding site from the regulatory region of the amyloid precursor protein gene in primary neuronal cultures. J. Biol. Chem., 271(25):15002-15007. [doi:10.1074/jbc.271.25.15002]

Hong, S.W., Shim, J.K., Choi, Y.S., et al., 2008. Prediction of cognitive dysfunction and patients' outcome following valvular heart surgery and the role of cerebral oximetry. Eur. J. Cardiothorac. Surg., 33(4):560-565. [doi:10.1016/ j.ejcts.2008.01.012]

Johnson, T., Monk, T., Rasmussen, L.S., et al., 2002. Postoperative cognitive dysfunction in middle-aged patients. Anesthesiology, 96(6):1351-1357. [doi:10.1097/00000542200206000-00014]

Karzai, W., Schwarzkopf, K., 2009. Hypoxemia during one-lung ventilation: prediction, prevention and treatment Anesthesiology, 110(6):1402-1411. [doi:10.1097/ALN. 0b013e31819fb15d]

Kienlen-Campard, P., Tasiaux, B., Octave, J.N., 2000. The processing and biological function of the human amyloid precursor protein (APP): lessons from different cellular models. Exp. Gerontol., 35(6-7):843-850. [doi:10.1016/ S0531-5565(00)00170-4]

Li, X.M., Shao, M.T., Wang, J.J., et al., 2014. Relationship between post-operative cognitive dysfunction and regional cerebral oxygen saturation and $\beta$-amyloid protein. J. Zhejiang Univ.-Sci. B (Biomed. \& Biotechnol.), 15(10): 870-878. [doi:10.1631/jzus.B1400130]

Lin, R., Zhang, F.J., Xue, Q.S., et al., 2013. Accuracy of regional cerebral oxygen saturation in predicting postoperative cognitive dysfunction after total hip arthroplasty. J. Arthroplasty, 28(3):494-497. [doi:10.1016/j.arth.2012.06.041]

Moller, J.T., Cluitmans, P., Rasmussen, L.S., et al., 1998. Longterm postoperative cognitive dysfunction in the elderly: ISPOCD1 study. Lancet, 351(9106):857-861. [doi:10. 1016/S0140-6736(97)07382-0]

Monk, T.G., Weldon, B.C., Garvan, C.W., et al., 2008. Predictors of cognitive dysfunction after majornoncardiac surgery. Anesthesiology, 108(1):18-30. [doi:10.1097/01. anes.0000296071.19434.1e]

Murkin, J.M., Adams, S.J., Novick, R.J., et al., 2007. Monitoring brain oxygen saturation during coronary bypass surgery: a randomized, prospective study. Anesth. Analg., 104(1):51-58. [doi:10.1213/01.ane.0000246814.29362.f4]

Olsen, K.S., Svendsen, L.B., Larsen, F.S., 1996. Validation of transcranial near-infrared spectroscopy for evaluation ofcerebral blood flow autoregulation. J. Neurosurg. Anesthesiol., 8(4):280-285. [doi:10.1097/00008506-19961 0000-00004]

Rasmussen, L.S., 2006. Postoperative cognitive dysfunction: incidence and prevention. Best Pract. Res. Clin. Anesth., 20(2):315-330. [doi:10.1016/j.bpa.2005.10.011]

Silverstein, J.H., Jefrey, H., 2007. Central nervous system dyrsfunction after noncardiac surgery and anesthesia in the elderly. Anesthesiology, 106(3):622-628. [doi:10.1097/ 00000542-200703000-00026]

Singh-Manoux, A., Kivimaki, M., Glymour, M.M., et al., 2012. Timing of onset of cognitive decline: results from Whitehall II prospective cohort study. BMJ, 344:d7622. [doi:10.1136/bmj.d7622]

Slater, J.P., Guarino, T., Stack, J., et al., 2009. Cerebraloxygen desaturation predicts cognitive decline and longer hospital stay after cardiac surgery. Ann. Thorac. Surg., 87(1):36-44. [doi:10.1016/j.athoracsur.2008.08.070]

Stephan, A., Laroche, S., Davis, S., 2003. Learning deficits and dysfunctional synaptic plasticity induced by aggregated amyloid deposits in the dentate gyrus are rescued by chronic treatment with indomethacin. Eur. J. Neurosci., 17(9):1921-1927. [doi:10.1046/j.1460-9568.2003.02610.x]

Townsend, K.P., Obregon, D., Quadros, A., et al., 2002. Proinflammatory and vasoactive effects of $\mathrm{A} \beta$ in the cerebrovasculature. Ann. NY. Acad. Sci., 977(1):65-76. [doi:10. 1111/j.1749-6632.2002.tb04799.x]

Yao, F.S.F., Tseng, C.C., Ho, C.Y.A., et al., 2004. Cerebral oxygen desaturation is associated with early postoperative neuropsychological dysfunction in patients undergoing cardiac surgery. J. Cardiothorac. Vasc. Anesth., 18(5):552-558. [doi:10.1053/j.jvca.2004.07.007]

\section{中文概要}

\section{题 目: 单肺通气术后认知功能障碍和脑氧饱和度关系的 研究}

目 的: 探讨单肺通气 (OLV) 患者术后认知功能障碍 (POCD) 与局部脑氧饱和度 $\left(\mathrm{rSO}_{2}\right)$ 的关系。

创新点: $\mathrm{POCD}$ 的发生与患者年龄及术中 $\mathrm{rSO}_{2}$ 较基础值下 降的最大百分数 $\left(\mathrm{rSO}_{2,}\right.$ \%max $)$ 密切相关, 术中 $\mathrm{rSO}_{2, \% \text { max }}>10.1 \%$ 时, 提示可能发生 POCD。术中 $\mathrm{rSO}_{2}$ 监测可作为 POCD 的预测手段。

方 法: 择期行 OLV 开胸手术患者 50 例（美国标准协会 （ASA）分级 I IIII），于术前 1 天和术后 7 天分 别进行神经心理测验。术中利用近红外光谱技术 (NIRS) 连续监测 $\mathrm{rSO}_{2}$, 并计算麻醉诱导前 $\left(t_{1}\right)$ 、 单肺通气开始 $\left(t_{2}\right)$ 、单肺通气 $30 \mathrm{~min}\left(t_{3}\right)$ 、单 肺通气 $60 \mathrm{~min}\left(t_{4}\right)$ 、单肺通气结束 $\left(t_{5}\right)$ 和手术 结束 $\left(t_{6}\right)$ 时刻的平均脑氧饱和度 $\left(\overline{\mathrm{rSO}}_{2}\right) 、 \mathrm{rSO}_{2}$ 最小值 $\left(\mathrm{rSO}_{2 \text { min }}\right)$ 和 $\mathrm{rSO}_{2, \% \max }$ 。

结 论: OLV 患者 POCD 的发生与 $\mathrm{rSO}_{2}$ 有关, $\mathrm{rSO}_{2}$ 监测 可能是预测发生 POCD 的有效手段之一。

关键词: 单肺通气; 术后认知功能障碍; 局部脑氧饱和度 